\title{
Numerical analysis of stresses at oblique holes in plates subjected to tension and bending
}

DOI:

10.1243/03093247V304317

\section{Document Version}

Accepted author manuscript

Link to publication record in Manchester Research Explorer

\section{Citation for published version (APA):}

Tafreshi, A., \& Thorpe, T. E. (1995). Numerical analysis of stresses at oblique holes in plates subjected to tension and bending. Journal of Strain Analysis For Engineering Design, 30(4), 317-323.

https://doi.org/10.1243/03093247V304317

\section{Published in:}

Journal of Strain Analysis For Engineering Design

\section{Citing this paper}

Please note that where the full-text provided on Manchester Research Explorer is the Author Accepted Manuscript or Proof version this may differ from the final Published version. If citing, it is advised that you check and use the publisher's definitive version.

\section{General rights}

Copyright and moral rights for the publications made accessible in the Research Explorer are retained by the authors and/or other copyright owners and it is a condition of accessing publications that users recognise and abide by the legal requirements associated with these rights.

\section{Takedown policy}

If you believe that this document breaches copyright please refer to the University of Manchester's Takedown Procedures [http://man.ac.uk/04Y6Bo] or contact uml.scholarlycommunications@manchester.ac.uk providing relevant details, so we can investigate your claim.

\section{OPEN ACCESS}




\title{
NUMERICAL ANALYSIS OF STRESSES AT OBLIQUE HOLES IN PLATES SUBJECT TO TENSION AND BENDING
}

\author{
A.TAFRESHI Division of Mechanical and Nuclear Engineering \\ The Manchester School of Engineering \\ University of Manchester.
}

\section{T.E.THORPE Division of Mechanical and Nuclear Engineering}

The Manchester School of Engineering

University of Manchester

Stress analysis of a series of thick, wide, flat plates with oblique holes subjected to uniaxial tension and out-of-plane bending has been carried out using the finite element method, and in some cases the boundary element method. Different plate thickness to hole diameter ratios, angles of hole obliquity and orientation have been considered to provide stress concentration factors at such holes. The work covers plate thickness to hole diameter ratios from 1.3 to 3.0, hole obliquity angles from 0 to 60 degrees and orientation of the major axis of the surface eilipse relative to the applied load direction of 0 to 90 degrees. The results for uniaxial tension have been compared with those determined using the photoelastic frozenstress technique in order to verify the finite element models before proceeding to the bending cases, which provide new data.

\section{INTRODUCTION}

An oblique hole is one whose axis is not normal to the surface which it penetrates. Oblique holes can be found at intersecting pipes and vessels, non-radial openings in cylindrical and spherical shells or lacing wire passages in steam-turbine blades.

Analytical solutions for stress distributions around an isolated circular or elliptical hole in a 
thin, infinite plate can be derived from the theory of elasticity (1). The stress distribution at a normal circular hole in a thick flat plate has also been studied and it has been shown that the mid-plane stress concentration is greater than that at the plate surface (2). In the case of oblique holes, most stress analyses have been carried out using the photoelastic technique (3)(4). The boundary element method has also been applied to a limited number of flat plates with oblique holes (5).

In a recent study (6), the magnitudes and positions of the principal stresses at a series of isolated oblique holes in thick, wide plates subjected to uniaxial tension were determined using the photoelastic frozen-stress technique. The model series covered nominal plate thickness to hole diameter ratios of $1.33,2.00$ and 3.00 , hole obliquity angles of $0,15,30$, 45 , and 60 degrees, and applied load directions of $0,30,60$ and 90 degrees relative to major axis of the surface ellipse. In another study (7) those results were used to provide stress concentration factors at such holes resulting from biaxial in-plane loading. The maximum and minimum principal stresses for a general case of in-plane loading were derived from the previous uniaxial data (6).

In the present work, the finite element method has been used to determine stresses around oblique holes in plates subject to out-of-plane bending. In order to verify the finite element models, uniaxial loading has also been considered and comparisons made with the results of reference (6). In some cases the boundary element method has also been used in the numerical analysis. 
Tafreshi, A. \& Thorpe, T. E. Oct 1995 In : Journal of Strain Analysis for Engineering Design. 30, 4, p. 317-323 7 p.

\section{NOTATION}

d Hole diameter

$h \quad$ Plate Thickness

$I_{1} \quad$ Normalized maximum principal stress

$I_{2} \quad$ Normalized minimum principal stress

$l \quad$ Plate length

$s \quad$ Linear coordinate parallel to hole axis

w Plate width

$z \quad$ Linear coordinate normal to mid-plane of plate

$\alpha \quad$ Angle between hole axis and plate normal. Range $0^{\circ}-90^{\circ}$

$\theta \quad$ Angular coordinate in plane normal to hole axis

v $\quad$ Poisson's ratio

$\Phi \quad$ Angle between major axis of elliptical intersection of hole in plane of plate and direction of applied uniaxial or bending stress. Range $0^{\circ}-90^{\circ}$ 


\section{STRESS ANALYSIS USING THE FINITE ELEMENT METHOD}

\subsection{Models analvsed}

Fig. 1. shows typical thick flat plate models for both tension and bending. Coordinates and symbols used to define the oblique hole are indicated.

Table 1 shows the dimensions of the plate models; these have been chosen to be the same as those in reference (6) for easy comparison. The width and length of each plate were such that the effects of the plate edges and boundary conditions on the hole stresses were negligible. As a result, infinite plate conditions were attained in the region of the hole. The model series covers a practical useful range of hole variables $(\alpha, \Phi, h / d)$. Table 2 shows the hole details.

\subsection{Mesh Generation and Element Type}

IDEAS (8) is a commercial CAD/CAE package which was used for pre- and post-processing of the finite element mesh and display of the results. Its mesh generator uses an automatic meshing technique that relies on triangulation to fill arbitrarily shaped regions. Either 4-node linear or 10 -node quadratic tetrahedral elements can be generated. Here for a better accuracy, quadratic elements were used. IDEAS was then interfaced with the general purpose finite element software, ABAQUS (9) to calculate stresses.

Different plate thicknesses with different hole obliquity angles were analysed. The number 
of tetrahedral elements varied from 700 to 3400 . The high number of elements resulted from the automatic meshing of the IDEAS package which minimised element distortion. Fig. 2a shows a typical finite element mesh and Fig. $2 \mathrm{~b}$ shows a close-up view of the nodes around the hole which are not uniformly distributed. To save computational cost and time, the meshes were refined in the critical area (around the hole), where the stresses had a rapid variation until convergence was achieved. Larger elements were used elsewhere. None of the elements were excessively elongated or distorted. In this way the number of elements was optimized to give accuracy at a reasonable cost. The angles, $\alpha$ and $\Phi$ were important parameters in the number of elements required for the models. For the high values of $\alpha$ and $\Phi$ the number of required elements was very high.

The computational analyses were carried out on HP735 and Cray EL98 computers.

\subsection{Boundary Conditions}

Two different types of loadings were considered, uniform uniaxial tension, and out-of-plane bending. For the case of uniaxial tension, the plate shown in Fig. 1a was subjected to uniform tensile stress, $\sigma$, in the $\mathrm{x}$-direction. This stress was given a value of unity so that stress values obtained were directly comparable to the stress indices of reference (6). The load was applied at one end of the plate, while the other end was fixed in the x-direction. For simulating out-of-plane bending, four thin bars were attached across the plate surfaces, two on the bottom at each end and two on the top, as shown in Fig. 1b. These were necessary to enable vertical loads to be applied to the finite element model. For comparison purposes the distance between the two bars attached to the top surface was equal to the length 
of the plate used for the axial loading case. Uniform pressures were applied on the top bars, while the bottom bars were fixed in the z-direction, an arrangement producing pure bending in the region of the hole.

\section{RESULTS}

\subsection{Uniaxial loading}

Table 2 shows the normalized maximum and minimum principal stresses, $I_{1}$ and $I_{2}$ for 22 different models of thick flat plates with oblique holes, calculated using the finite element method. The maximum values of the stress indices $I_{1}$ and $I_{2}$ from the photoelastic analysis of similar models (6) are also presented, and are directly comparable with the $I_{1}$ and $I_{2}$ values of this work.

Various combinations of $\alpha$ (varying from 0 to $\left.60^{\circ}\right), \mathrm{h} / \mathrm{d}(1.33$ to 2.00$)$ and $\phi\left(0\right.$ to $\left.90^{\circ}\right)$ were considered, as indicated in the table. For each case the minimum number of finite elements necessary to produce convergence is also noted.

The $I_{1}$ values from the finite element analyses differ from those of the photoelastic work, with one exception, (case no.18), by less than $9 \%$, which represents acceptably good agreement. The angular positions of the peak stresses found in the numerical analysis, as indicated, for example, in the contour plot of Figure 6, compare well with photoelastic results. However, the finite element results indicate that these peak values lie on the plate surface, whereas the photoelastic work suggest that they lie within the plate thickness. 
For the $I_{2}$ values the absolute differences between values from the numerical and experimental results are of comparable magnitude to those for the $I_{1}$ results, but being smaller values, the percentage differences are much greater.

The variation of peak stresses with $\phi$, for constant values of $h / d$ and $\alpha$, (Fig.3) and with $\alpha$, for constant values of $h / d$ and $\phi$, (Fig.4) show the same general trends in both the numerical and experimental work, and therefore give confidence in the finite element modeis.

Further verification of the finite element work can be gained from Case No. 1, in which the hole is normal to the plate. The magnitudes of the peak stress values are in good agreement with the analytical solution (2).

Some more cases with $\alpha=60^{\circ}$ were analysed which are not presented here. The FE results for those cases were about $20-30 \%$ higher than photoelastic results. In modelling them the IDEAS package warned of a large number of distorted elements around the hole because of the high angle of obliquity. In order to remove the distorted elements, the total number of elements would have had to be increased, causing problems with the limitation on computational time and capacity.

It is not practical to give detailed stress distributions for each hole, but the results for hole No. $17\left(\alpha=45^{\circ}, \Phi=30^{\circ}, \mathrm{h} / \mathrm{d}=1.33\right.$ ) are presented as a typical example. This is similar to the case presented in detail in Reference (6) in which contour plots were constructed manually. Here the contour plots (Figs. 5 and 6) of the normalized maximum and minimum principal 
Tafreshi, A. \& Thorpe, T. E. Oct 1995 In : Journal of Strain Analysis for Engineering Design. 30, 4, p. 317-323 7 p.

stresses on a development of the hole surface have been generated using the UNIRAS (10) software. The number of nodes around the hole was about 220 with non-uniform distribution. The bilinear method was used for interpolation of the stresses. The maximum $I_{1}$ value of 3.20 occurred at the plate surface and at $\theta=37.5^{\circ}$. This is close to the point where the applied stress direction is tangential to the hole rim. The maximum $I_{2}$ value of -1.44 also occurred at the plate surface but at $\theta=163^{\circ}$. This agrees with the experimental results as far as angular position is concerned. The latter gives the position of the maximum principal stress approaching the acute edge of the hole, close to the point where the applied stress direction is tangential to the hole rim. However, the experimental results indicate that the maximum stress is some way from the plate surface.

It should be mentioned that for a plate with an oblique hole there is no plane of symmetry but there is a centre of symmetry. It means that for each point on the hole surface there is a corresponding point at which the stress state is identical. However, because of the nonuniform distribution of the finite element nodes around the hole, as shown in Fig. $2 b$, the stress values at each pair of symmetrical points in the contour plots of Figs. $5 \& 6$, are not exactly the same.

\subsection{Out-of-Plane Bending}

Four of the plates with oblique holes listed in Table 2 were analysed under out-of-plane bending loads. The present author's are not aware of any comparable experimentral results for these cases. The maximum principal stresses were normalised with respect to the tensile stress on the surface of the same plate without a hole under the same bending moment. Table 2 shows the results for bending, alongside the axial loading results for the same hole 
configuration. The ratios of $I_{1}$ (bending) to $I_{1}$ (tension) are between 0.68 and 0.76 .

\section{STRESS ANALYSIS USING THE BOUNDARY ELEMENT METHOD}

The boundary element method (BEM) is an attractive alternative to the finite element technique for a wide range of applications in stress analysis. It is particularly well established for linear elastic problems, and has a number of advantages over the finite element technique (11). It greatly simplifies mesh data preparation, because only the surface of the component or structure to be analysed needs to be discretized. It needs less computing time and storage for the same level of accuracy because within the solution domain the governing differential equations are satisfied exactly, rather than approximated as in the case of the finite element method. In using the boundary element method, less unwanted information about internal points is obtained.

Abdul-Mihsein et al (5) used the BEM for analysis of plates with oblique holes. They analysed a limited number of models in which the load direction was parallel to the major axis of the surface ellipse of the hole, i.e. $\Phi=0$, and compared their results with experimental results. Because of the limitation in computer time and capacity they only used up to 80 parabolic quadrilateral elements. In cases where this limitation was reached, their results showed large discrepancies compared with experimental results.

In order to investigate the value of the BEM for the oblique hole problem, some of the present models have been analysed by this method. Here the same program as (5) and (12) has been used, with slight modification to allow execution on a Hewlett Packard system. The 
BEM program was interfaced with IDEAS for pre- and post-processing. The number of boundary elements for the models have been doubled. Three different models of plates with oblique holes were considered. Table 3 shows the BEM, FEM and experimental results for these holes. Another case with $\alpha=60^{\circ}$ was analysed, but is not presented here. The BEM results were up to $40 \%$ higher than FEM and experimental results. For the normal hole and the hole with low angle of obliquity the available BEM program was quite capable of handling the models. For greater angles of obliquity, larger numbers of elements were required, which resulted in problems due to the limitation on computational time and capacity. However, for the normal hole (case no.1 in Table 4) where the number of boundary elements is $1 / 9$ of the number of finite elements and case no. 2 where the number of boundary elements is $1 / 14$ of the number of finite elements, the BEM gives good accuracy.

\section{CONCLUSIONS}

A series of thick flat plates with oblique holes under uniaxial tension and out-of-plane bending were analysed using the finite element and boundary element methods. For the uniaxial loading case, the maximum tensile stresses $\left(I_{1}\right)$ and maximum compressive stresses

$\left(I_{2}\right)$ were compared with results obtained by experimental photoelastic technique. For the $I_{1}$ values the differences between the FE results and experimental results were within $8.6 \%$ which showed good agreement. For $\mathrm{I}_{2}$ values the differences were within $37 \%$. These differences were large, even for models with dense meshes in the critical regions and without distorted elements. The reasons for this warrant further study. 
Models with holes at large angles of obliquity required large numbers of elements in order to achieve reliable results but such numbers of elements were beyond the limitations on computer time and space. So for $\alpha=60^{\circ}$ for example, the accuracy of FE results was very poor and the differences between the FE results and experimental results were about $20-30 \%$.

Plates with oblique holes under out-of-plane bending were analysed using the FEM. Comparing the bending results with axial loading results showed that the ratio $I_{1}$ (bending) $/ I_{1}$ (tension) is between 0.68 and 0.76 .

Models under uniaxial tension were also analysed using the boundary element method. The results showed that for the lower angles of obliquity, where the required number of elements was low, the accuracy of the boundary element method in comparison with the finite element method was very good. This was so even when the number of finite elements was about 9 times the number of boundary elements. For higher angle of obliquity ( $\alpha$ greater than $30^{\circ}$ ) the BEM showed higher values for $I_{1}$ in comparison with the FEM and experimental results.

\section{ACKNOWLEDGEMENTS}

The authors wish to thank Professor R T Fenner (Imperial College) for letting us to use the three-dimensional BEM program (12) and Professor P Stanley, (University of Manchester), co-author of the photoelastic work (6), for his encouragement and constructive comments. 
REFERENCES

(1) Timoshenko, S. and Goodier, J.N., "Theory of Elasticity", 1951, Second Edition (McGraw-Hill, New York), pp 78-85

(2) Youngdahl, C.K. and Sternberg, E., "Three-dimensional stress concentration around a cylindrical hole in a semi-infinite elastic body", J. Appl. Mech., 1966, 33, 855865

(3) Meyer,L.J. and Macke,H.J., "Photoelastic stress analysis of a pattern of oblique holes in jet engine hardware", Proceedings of VIIth international congress on experimental mechanics, Las Vegas, 1992, Vol. 1, 550-555

(4) Leven, M.M., "Photoelastic determination of the stresses at oblique openings in plates and shells", WRC Bulletin No. 153, 1970, p 52-80

(5) M.J.Abdul-Mihsein, R.T.Fenner \& C.L.Tan, "Boundary Integral Equation Analysis of Elastic Stresses Around an Oblique Hole in a Flat Plate", Journal of Strain Analysis, Vol 14, No.4, 1979, pp 179-185

(6) P.Stanley and B.V.Day, "Photoelastic Investigation of Stresses at an Oblique Hole in a Thick Flat Plate Under Uniform Uniaxial Tension", Journal of Strain Analysis, Vol 25 , No 3, 1990, pp 157-175 
Tafreshi, A. \& Thorpe, T. E. Oct 1995 In : Journal of Strain Analysis for Engineering Design. 30, 4, p. 317-323 7 p.

(7) P.Stanley and B.V.Day, "Stress Concentrations at an Oblique Hole in a Thick Flat Plate Under an arbitrary In-Plane Biaxial Loading", Journal of Strain Analysis, Vol 28, No. 3, 1993, pp 223-235

(8) IDEAS (Integrated Design Engineering Analysis Software), Solid modelling and Finite Element Modelling User's Manual, (Structural Dynamics Research Corporation, USA, 1993)

(9) ABAQUS User's Manual, Version 5.3 (Hibbit, Karlson \& Sorensen Inc., Providence, RI, 1993)

(10) UNIRAS Users's Guide, Version 6.3a (UNIRAS A/S, Denmark), 1992

(11) A.Tafreshi and R.T.Fenner, "Design Optimization Using the Boundary Element Method", J. Strain Analysis, Vol. 26, No. 4, 1991, pp 231-241

(12) Tan, C. L., "Three-Dimensional Boundary Integral Equation Stress Analysis of Cracked Components", PhD Thesis, Imperial College, University of London, 1979 


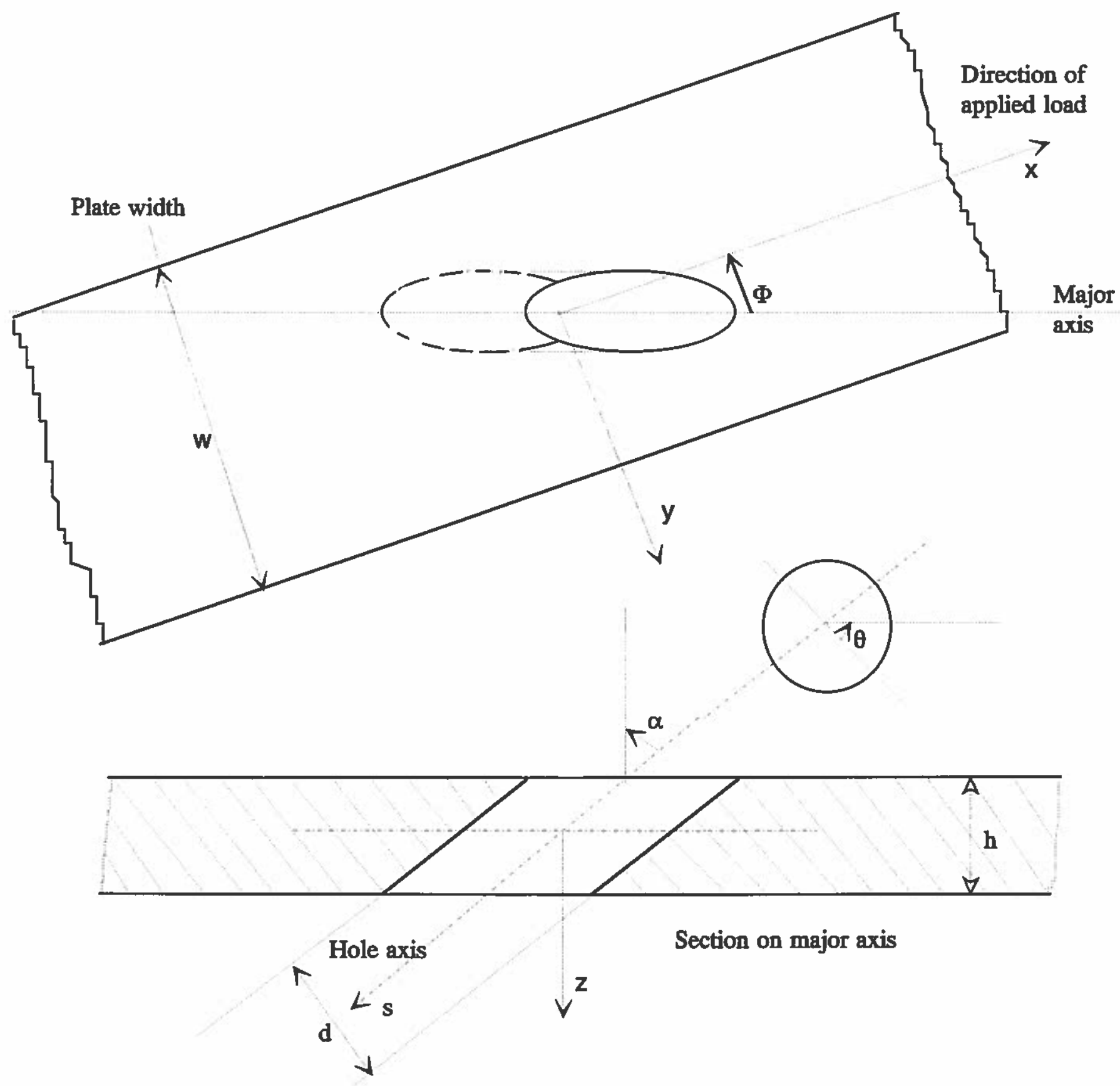

Fig. 1. Oblique circular-cylindrical hole in a flat plate: coordinates and symbols

(a) Plate model for tension

(b) Plate model for bending 


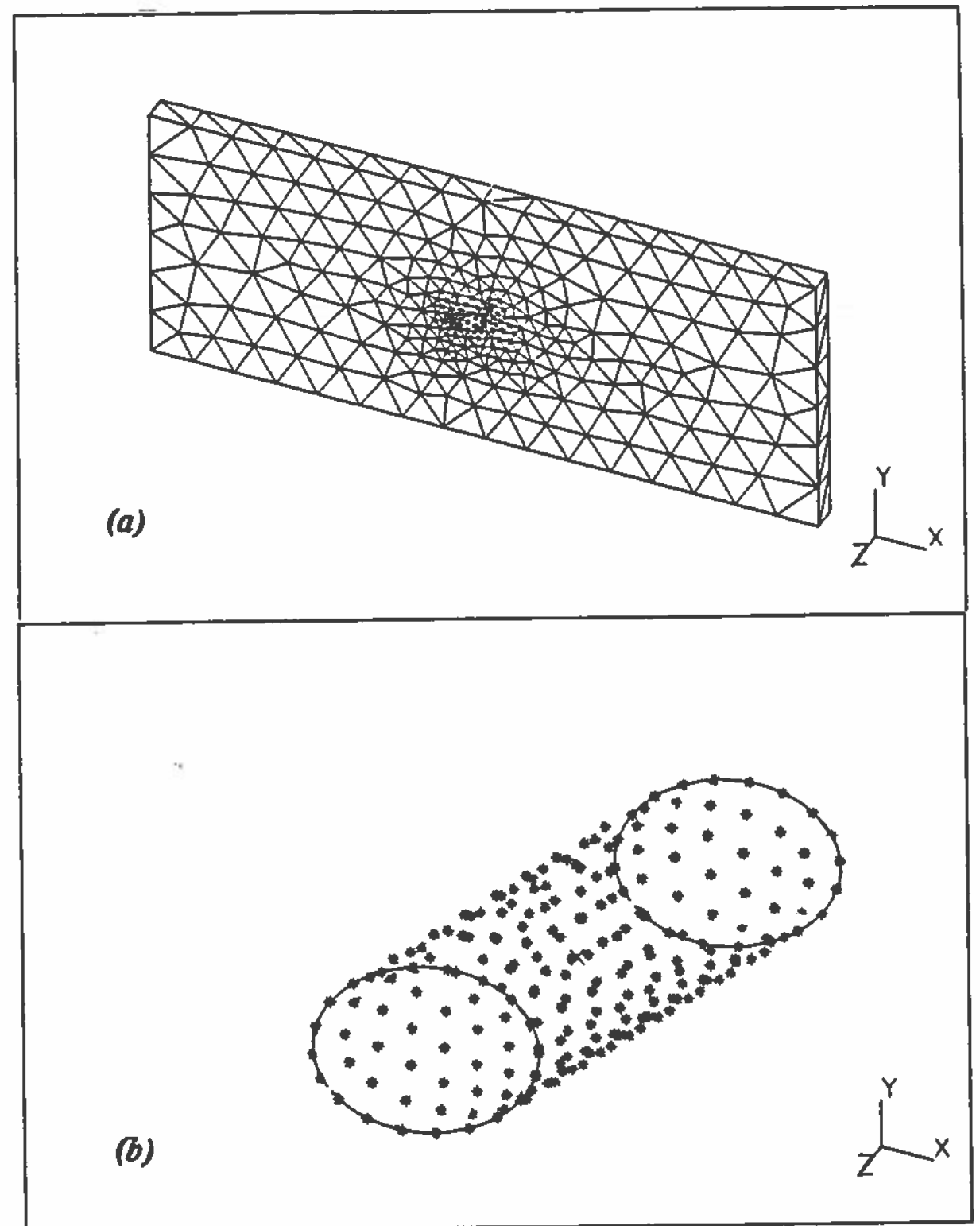

Fig. 2 (a) Typical finite element mesh for a flat plate with an oblique hole (b) Close up view of the nodes around the hole 
Tafreshi, A. \& Thorpe, T. E. Oct 1995 In : Journal of Strain Analysis for Engineering Design. 30, 4, p. 317-323 7 p.

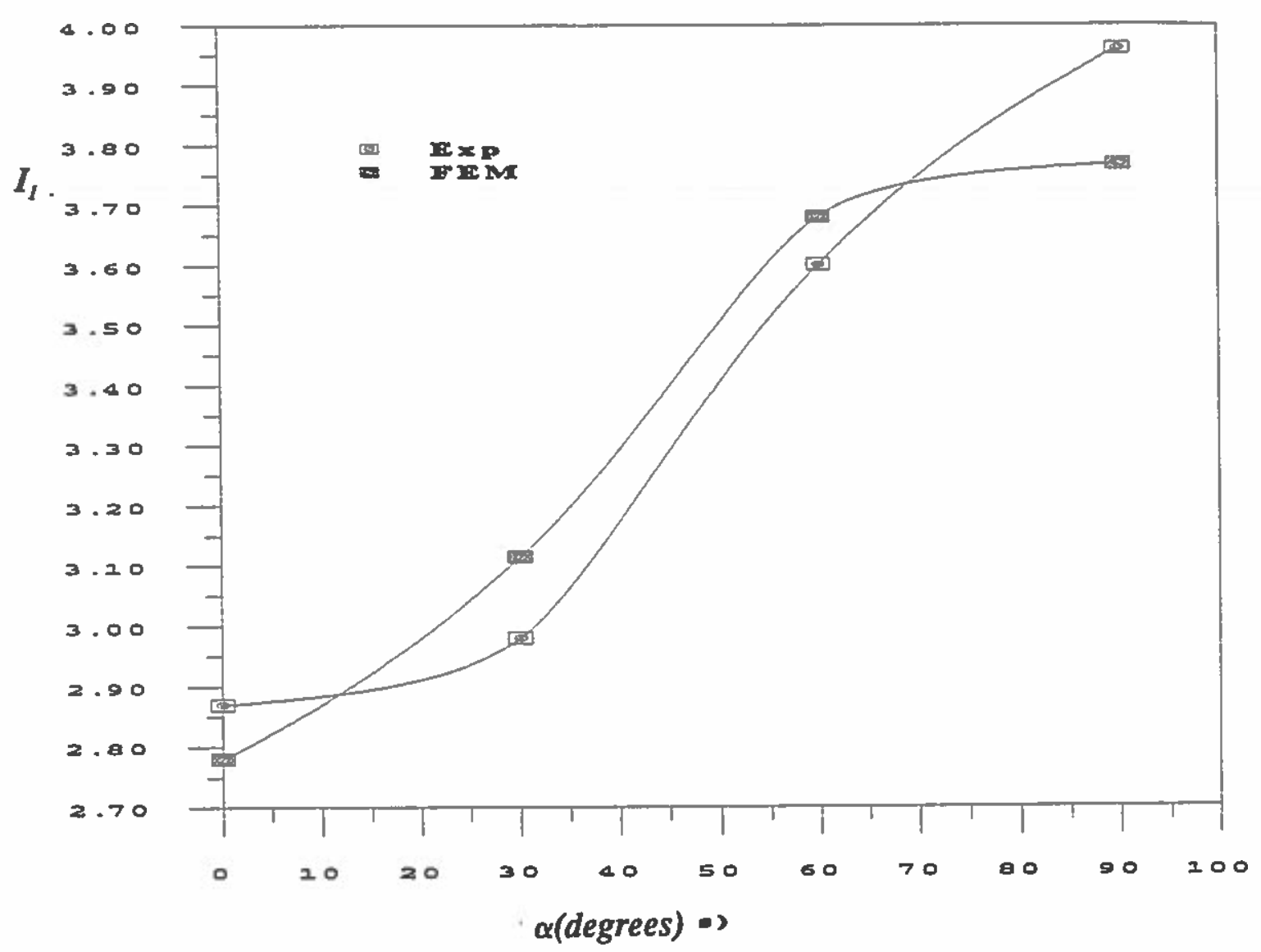

Fig. 3 Variation of $I_{1}$ with respect to $\Phi$ for plates under uniform uniaxial tension with $h / d=1.33$ and $\alpha=30^{\circ}$, Experimental (6) and $F E$ results 
Tafreshi, A. \& Thorpe, T. E. Oct 1995 In : Journal of Strain Analysis for Engineering Design. 30, 4, p. 317-323 7 p.

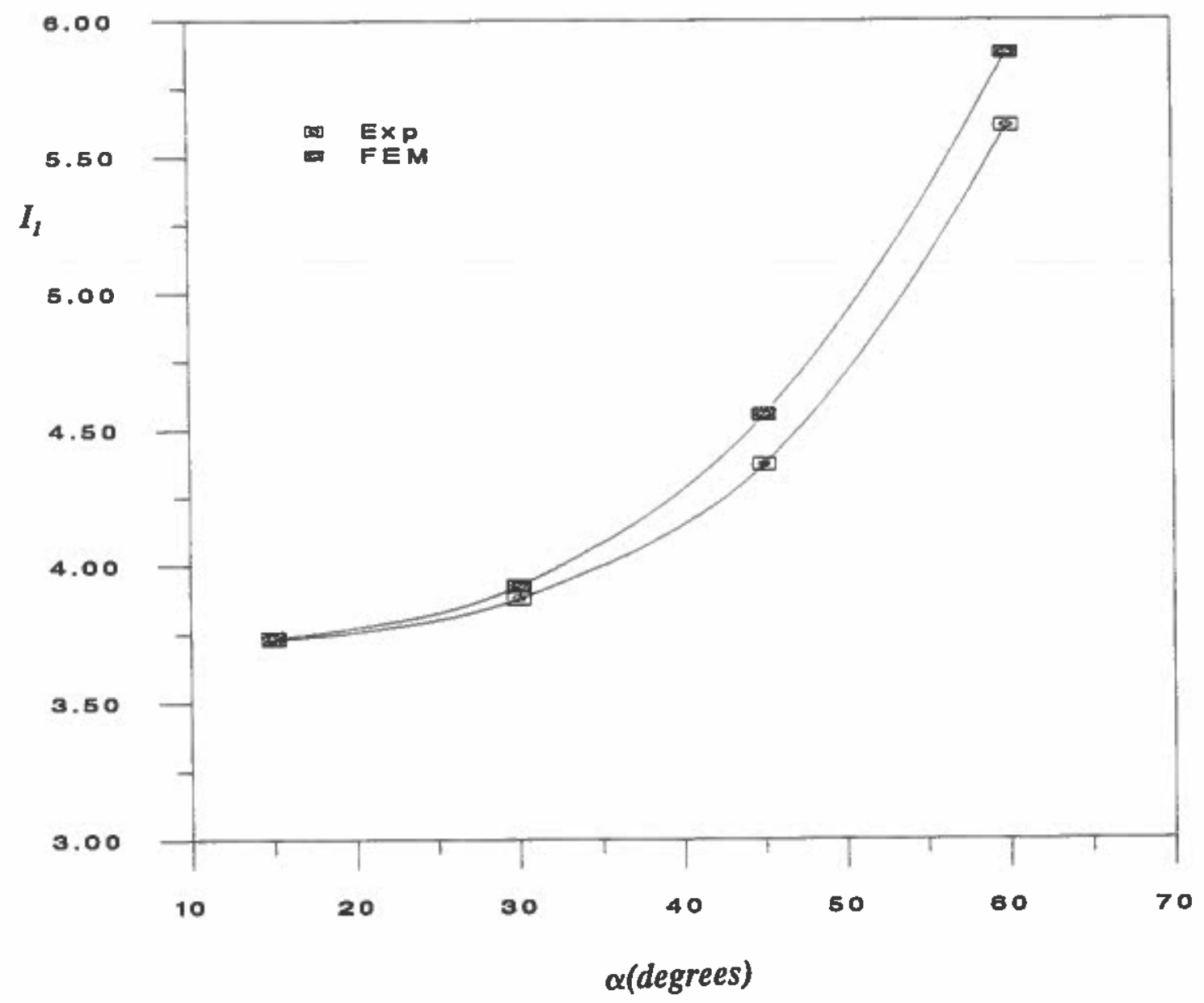

Fig. 4 Variation of $I_{1}$ with respect to $\alpha$ for plates under uniform uniaxial tension with $h / d=2.0$ and $\Phi=90^{\circ}$, Experimental (6) and $F E$ results 


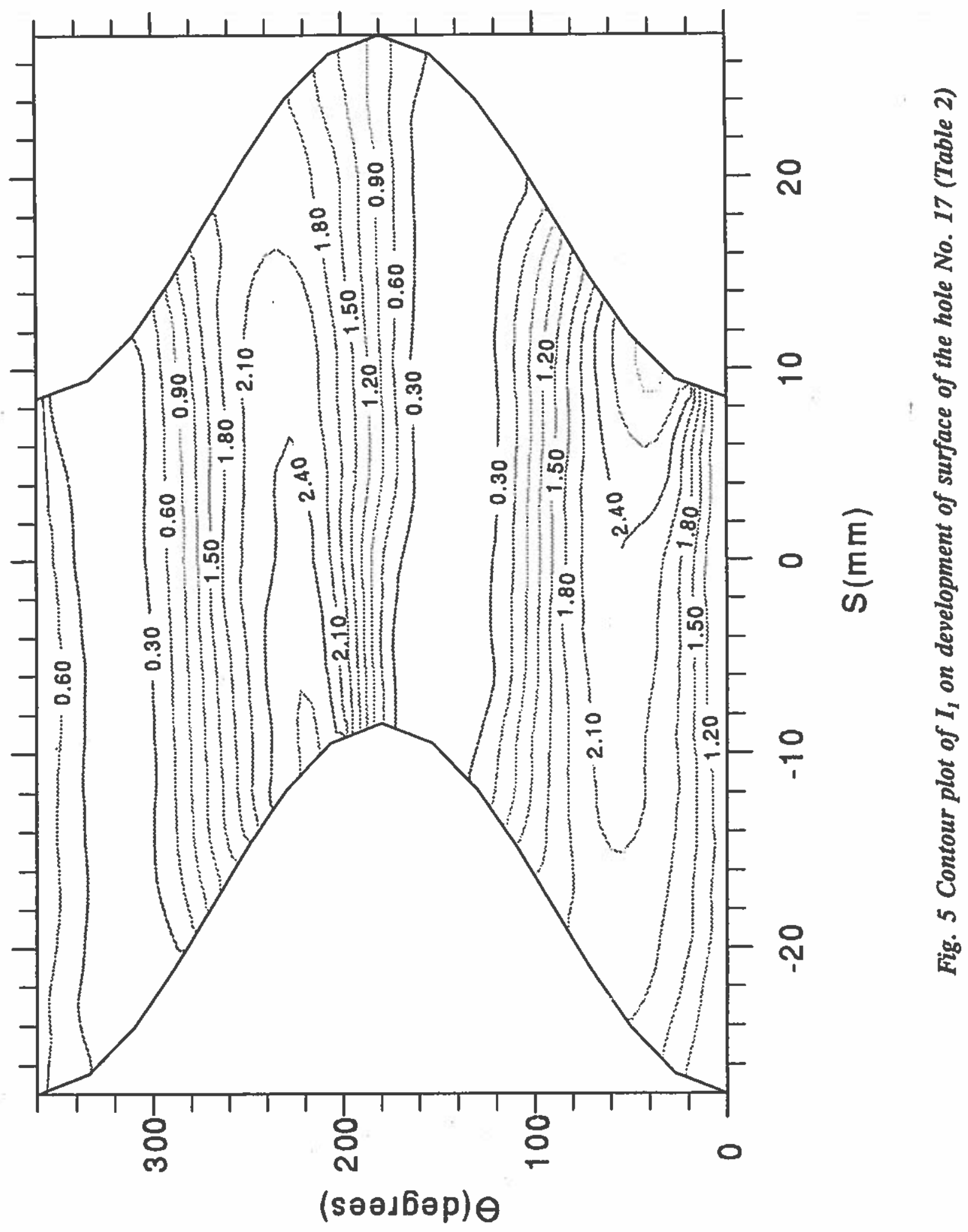




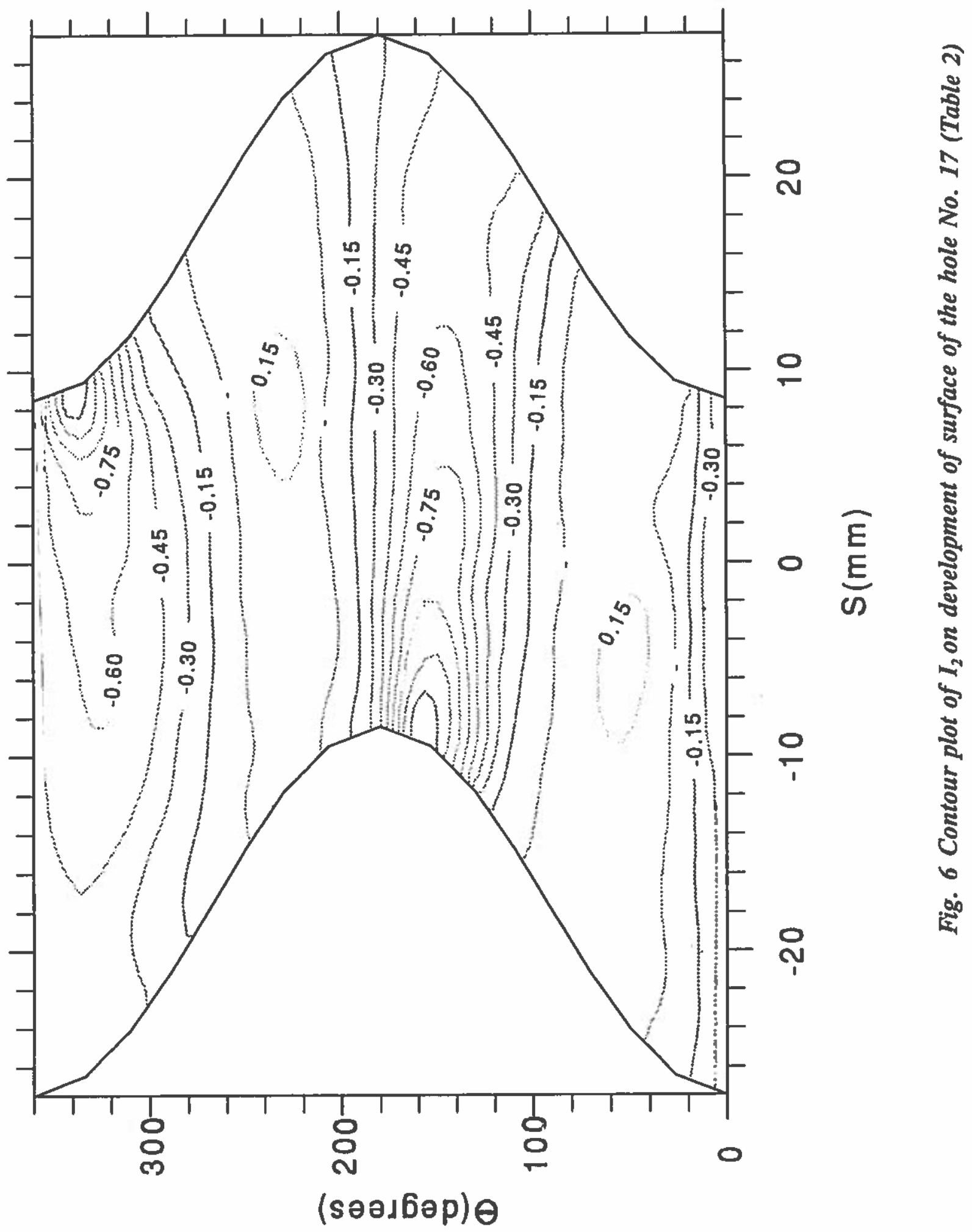


Tafreshi, A. \& Thorpe, T. E. Oct 1995 In : Journal of Strain Analysis for Engineering Design. 30, 4, p. 317-323 7 p.

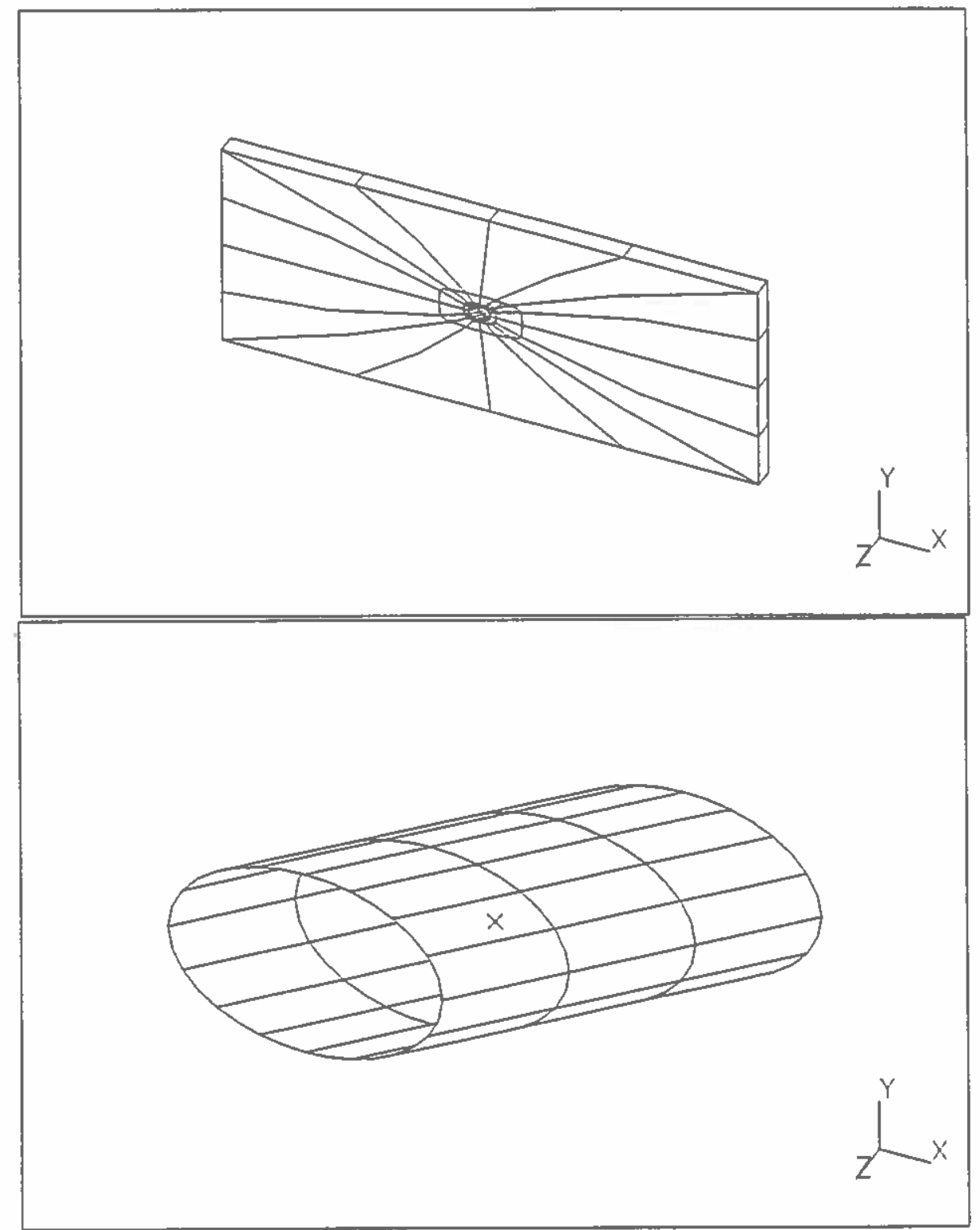

Fig. 7 (a) Typical boundary elementmesh for a flat plate with an oblique hole (160 elements) (b) Close up view of the elements around the hole 
Tafreshi, A. \& Thorpe, T. E. Oct 1995 In : Journal of Strain Analysis for Engineering Design. 30, 4, p. 317-323 7 p.

Table 1 Dimensions of plate models

\begin{tabular}{||c|c|c|c|c||}
\hline $\begin{array}{c}\text { Thickness } \\
\text { (mm) }\end{array}$ & $\begin{array}{c}\text { Width } \\
w(m m)\end{array}$ & $\begin{array}{c}\text { Length } \\
l(\mathbf{m m})\end{array}$ & $\begin{array}{c}\text { Hole } \\
\text { diameter } \\
\mathbf{d}(\mathbf{m m})\end{array}$ & $\begin{array}{c}\text { Ratio } \\
\boldsymbol{h} / \boldsymbol{d}\end{array}$ \\
\hline 25.4 & 254 & 650 & 19.0 & 1.33 \\
\hline 50.8 & 305 & 650 & 25.4 & 2.0 \\
\hline 50.8 & 305 & 650 & 16.9 & 3.0 \\
\hline
\end{tabular}


Tafreshi, A. \& Thorpe, T. E. Oct 1995 In : Journal of Strain Analysis for Engineering Design. 30, 4, p. 317-323 7 p.

Table 2 Values of $I_{1}$ and $I_{2}$ in flat plates with oblique holes under

a) uniform uniaxial tension, Experimental(6) and FE results

b) Out-of-Plane bending (FE results only)

\begin{tabular}{|c|c|c|c|c|c|c|c|c|c|}
\hline \multirow[b]{2}{*}{ No. } & \multirow[b]{2}{*}{$a$} & \multirow[b]{2}{*}{$h / d$} & \multirow[b]{2}{*}{$\Phi$} & \multicolumn{5}{|c|}{ (a) } & \multirow{2}{*}{$\frac{(b)}{I_{1}(\text { FEM })}$} \\
\hline & & & & $\mathrm{I}_{1}$ (Exp.) & I,(FEM) & $\mathrm{I}_{2}($ Exp) & $\mathrm{I}_{2}($ FEM $)$ & Elems & \\
\hline 1 & 0. & 1.33 & - & 3.31 & 3.18 & -1.00 & -0.91 & 720 & 2.18 \\
\hline 2 & 15 & 1.33 & 0 & 3.16 & 3.09 & -1.36 & -1.22 & 850 & \\
\hline 3 & 15 & 1.33 & 30 & 3.23 & 3.22 & -1.28 & -1.13 & 949 & \\
\hline 4 & 15 & 1.33 & 60 & 3.38 & 3.35 & -1.31 & -1.04 & 833 & 2.26 \\
\hline 5 & 15 & 1.33 & 90 & 3.73 & 3.40 & -1.41 & -1.15 & 794 & \\
\hline 6 & 15 & 2.00 & 0 & 3.15 & 3.07 & -1.44 & -1.29 & 1162 & \\
\hline 7 & 15 & 2.00 & 90 & 3.73 & 3.73 & -1.54 & -0.96 & 1028 & \\
\hline 8 & 15 & 3.00 & 30 & 3.25 & 3.20 & -1.06 & -0.98 & 2184 & \\
\hline 9 & 30 & 1.33 & 0 & 2.87 & 2.78 & -1.20 & -1.32 & 908 & \\
\hline 10 & 30 & 1.33 & 30 & 2.98 & 3.11 & -1.18 & .1 .22 & 2300 & \\
\hline 11 & 30 & 1.33 & 60 & 3.60 & 3.68 & -1.44 & -1.11 & 836 & \\
\hline 12 & 30 & 1.33 & 90 & 3.96 & 3.76 & -1.59 & -1.15 & 797 & \\
\hline 13 & 30 & 2.00 & 90 & 3.88 & 3.92 & -1.36 & -1.12 & 967 & \\
\hline 14 & 30 & 3.00 & 30 & 3.26 & 3.08 & -1.41 & -1.158 & 1680 & \\
\hline 15 & 30 & 3.00 & 90 & 3.90 & 3.60 & -1.62 & -1.215 & 1589 & \\
\hline 16 & 45 & 1.33 & 0 & 2.52 & 2.59 & -1.43 & -2.10 & 2313 & 1.83 \\
\hline 17 & 45 & 1.33 & 30 & 2.95 & 3.20 & -1.52 & -1.44 & 2097 & \\
\hline 18 & 45 & 1.33 & 60 & 3.65 & 4.51 & -1.55 & -1.27 & 2239 & \\
\hline 19 & 45 & 1.33 & 90 & 4.32 & 4.49 & -1.61 & -1.17 & 2202 & 3.42 \\
\hline 20 & 45 & 2.00 & 90 & 4.37 & 4.55 & $-1,60$ & -1.115 & 2984 & \\
\hline 21 & 45 & 3.00 & 90 & - & 4.40 & $\therefore$ & -1.139 & 2850 & \\
\hline 22 & 60 & 2.00 & 90 & 5.61 & 5.87 & -1.73 & -1.211 & 3391 & \\
\hline
\end{tabular}


Tafreshi, A. \& Thorpe, T. E. Oct 1995 In : Journal of Strain Analysis for Engineering Design. 30, 4, p. $317-3237$ p.

Table 3 Values of $I_{1}$ in flat plates under uniform uniaxial tension using the finite element method, boundary element method and experimental technique (6)

\begin{tabular}{|c|c|c|c|c|c|c|c|c|}
\hline \multirow[t]{2}{*}{ No } & \multirow[t]{2}{*}{$a$} & \multirow[t]{2}{*}{$h / d$} & \multirow[t]{2}{*}{$\Phi$} & \multirow[t]{2}{*}{$I_{1(E \times p .)}$} & \multirow[t]{2}{*}{$I_{\text {(FEM) }}$} & \multirow[t]{2}{*}{$\mathbf{I}_{\text {(BEM) }}$} & \multicolumn{2}{|c|}{ No. of Elems } \\
\hline & & & & & & & FEM & BEM \\
\hline 1 & 0. & 1.33 & - & 3.31 & 3.18 & 3.28 & 720 & 80 \\
\hline 2 & 45 & 1.33 & 0 & 2.52 & 2.59 & 2.72 & 2313 & 160 \\
\hline 3 & 45 & 1.33 & 30 & 2.95 & 3.20 & 4.23 & 2097 & 156 \\
\hline
\end{tabular}

